\title{
Overexpression of sphingosine kinase 1 is predictive of poor prognosis in human breast cancer
}

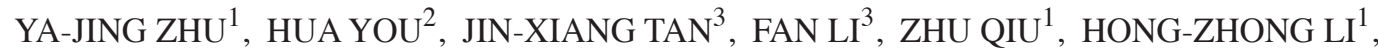 \\ HONG-YAN HUANG ${ }^{1}, \mathrm{KE} \mathrm{ZHENG}^{1,3}$ and GUO-SHENG REN ${ }^{1,3}$
}

\begin{abstract}
${ }^{1}$ Molecular Oncology and Epigenetics Laboratory, The First Affiliated Hospital of Chongqing Medical University, Yuzhong, Chongqing 400016; ${ }^{2}$ Department of Lymphoma, Head and Neck Oncology, Affiliated Hospital of Academy of Military Medical Sciences, Fengtai, Beijing 100071; ${ }^{3}$ Department of Endocrine and Breast Surgery, The First Affiliated Hospital of Chongqing Medical University, Yuzhong, Chongqing 400016, P.R. China
\end{abstract}

Received January 31, 2016; Accepted February 22, 2017

DOI: $10.3892 / \mathrm{ol} .2017 .6134$

\begin{abstract}
Sphingosine kinase 1 (SPHK1) is a bioactive lipid mediator that has been identified as a biomarker in various cancers and is considered to play an important role in tumor progression. In the present study, the expression level of SPHK1 was examined in breast cancer clinical specimens, and its association with patient survival was investigated to clarify the clinical significance of SPHK1 in breast cancer. SPHK1 mRNA expression was increased in breast cancer tissues compared with that in matched adjacent breast tissues in 19 of 32 paired tissue specimens (59.4\%). Immunohistochemical analysis of 122 breast cancer cases revealed that the expression levels of SPHK1 were upregulated in 64 tumor tissues (52.5\%), and increased expression levels of the protein were significantly associated with the presence of lymph node metastasis $(\mathrm{P}=0.0016)$, number of positive lymph nodes $(\mathrm{P}=0.0268)$ and presence of distant metastasis $(\mathrm{P}=0.0097)$. Increased SPHK1 protein expression was also associated with human epidermal growth factor receptor 2 status $(\mathrm{P}=0.0100)$, initial symptoms $(\mathrm{P}=0.0025)$ and tumor location $(\mathrm{P}=0.0457)$. Patients with increased SPHK1 protein expression had shorter overall survival and disease-free survival times compared with patients with lower SPHK1. Univariate and multivariate analyses indicated that high SPHK1 expression may be a poor prognostic factor. These results indicated that SPHK1 may perform an important role in breast cancer and may be a predictive factor in patients with breast cancer.
\end{abstract}

Correspondence to: Professor Guo-Sheng Ren or Dr Ke Zheng, Department of Endocrine and Breast Surgery, The First Affiliated Hospital of Chongqing Medical University, 1 Youyi Road, Yuzhong, Chongqing 400016, P.R. China

E-mail:rgs726@163.com

E-mail: kezheng81@163.com

Key words: sphingosine kinase 1, breast cancer, lymph node metastasis, prognosis, immunohistochemistry

\section{Introduction}

Breast cancer is the leading cause of cancer-associated mortality in women worldwide; $\sim 1.38$ million new breast cancer cases and $\sim 0.46$ million breast cancer-associated mortalities were estimated to have occurred in 2014 (1). In China, the incidence has increased more than twice as fast as global rates since the $1990 \mathrm{~s}$, and is now the most frequently diagnosed cancer and the sixth leading cause of cancer-associated mortality among Chinese women (2). Despite an increase in the five-year survival rate of breast cancer, as a result of early diagnosis and improved local and systemic treatment over the last 20 years, long-term prognosis remains unsatisfactory, mainly due to the recurrence and invasion rates following resection (3). However, little is known about this aggressive behavior. Finding new favorable prognostic biomarkers may help to predict the properties of the malignancy, thus decreasing the rate of unsatisfied outcomes in a high-risk population.

The oncogenic enzyme sphingosine kinase (SPHK) catalyzes the phosphorylation of sphingosine to form sphingosine-1-phosphate, which is suggested to be a bioactive lipid mediator that serves a vital role in regulating various biological processes during tumorigenesis (4). Two functional SPHK isoenzymes, SPHK1 and SPHK2, have been identified in humans (5). Multiple lines of evidence indicate that SPHK1 regulates various processes important for cancer progression (6,7); however, there are limited studies regarding biological functions of SPHK 2 in cancer, and it remains unclear whether SPHK1 and SPHK2 have redundant, overlapping, complementary or antagonistic functions in human cancer cells. A previous study showed that downregulation of SPHK2 in MDA-MB- 453 breast cancer cells completely eliminated migration towards epidermal growth factor (EGF), suggesting it is similar to SPHK1 (8). Other studies hypothesized that overexpression of SPHK2 suppresses growth and enhances apoptosis, preceded by cytochrome $c$ release and activation of caspase- $3(9,10)$, indicating that the two isoenzymes have opposite effects. An additional study suggested that non-small cell lung cancer patients with higher SPHK2 expression had a shorter overall survival (OS) time (11). The present study was only focused on the role of SPHK1, instead of SPHK2, 
in breast cancer long-term survival, since there are a larger number of studies providing evidence of its role in patients with cancer prognosis, thereby supporting the hypothesis.

SPHK1 mRNA has been revealed to be frequently overexpressed in a variety of human solid tumors (12). Other studies have demonstrated that SPHK1 protein expression is unregulated in various types of cancer, including prostate cancer (13), gastric cancer (14), glioblastoma multiforme (15), intestinal adenoma (16), acute erythroleukemia (17), colon cancer (18), salivary gland carcinoma (19) and glioma (20). In addition, there is plenty of evidence indicating that activation of SPHK1 is associated with anti-apoptosis effects, and the transformation, proliferation and survival of tumor cells $(21,22)$. Furthermore, while SPHK1 activity may be stimulated by a variety of cellular stimuli, and anticancer treatments may cause downregulation of SPHK1 activity, it has been suggested that the SPHK1 inhibitors camptothecin and docetaxel suppress tumor growth as well as reduce the occurrence and number of metastases in nude mice (23).

A previous study reported that downregulation of SPHK1 in MCF-7 cells could reduce EGF- and serum-stimulated grow th and enhance sensitivity to doxorubicin (a potent chemotherapeutic agent), suggesting that SPHK1 may perform an important role in the migration of MCF-7 cells (24). Increased expression of SPHK1 has been detected in triple-negative human breast tumors compared with receptor-positive tumors, and the SPHK1 ectopic expression is associated with poor overall and progression-free survival in breast cancer patients, as well as poor response to doxorubicin-based treatment (25). These observations propose that SPHK1 may be involved in cell growth and transformation in cancer progression.

However, there are limited studies connecting a comprehensive investigation of the expression and significance of SPHK1 with the long-time prognosis in patients with breast cancer in China. In the present study, the expression of SPHK1 was assessed in mRNA and protein levels in breast cancer tissues and compared with the clinicopathological parameters and survival of patients in 122 breast cancer patients. The present results indicated that SPHK1 may be a promising potential biomarker for predicting the prognosis of patients with breast cancer and a promising new target for breast cancer therapy.

\section{Materials and methods}

Patients and specimens. The analysis of human tissues was approved by the Human Research Ethical Committee of Chongqing Medical University (CQMU; Chongqing, China). Informed consent was obtained from all patients or their relatives. A total of 32 breast tumors and paired surgical-margin tissues ( $>1 \mathrm{~cm}$ away from the tumor area) were obtained from the First Affiliated Hospital of CQMU (Chongqing, China). Tissues to be subjected to RNA extraction were frozen in liquid nitrogen. Tissue samples from 122 patients who underwent surgical resection for primary invasive breast cancer at the First Affiliated Hospital of CQMU between December 2006 and November 2013 were collected. All samples were evaluated and subject to histological diagnosis by pathologists. Subsequent to surgery, the majority of patients were treated with the standard practice guidelines at that time and were followed up regularly. In total, 15 normal breast specimens were obtained from the defect border while removing a benign breast tumor using the Mammotome biopsy technique (26). Formalin-fixed, paraffin-embedded materials were used for routine staining with hematoxylin and eosin (H\&E; Zhongshan Jinqiao, Beijing, China) and for staining by immunohistochemical techniques. Grading of tumors was achieved by staining with $\mathrm{H} \& \mathrm{E}$.

$R N A$ extraction and reverse transcription-quantitative polymerase chain reaction $(R T-q P C R)$. Total RNA was isolated from the tissue of patients using TRIzol reagent (Molecular Research Center, Cincinnati, OH, USA). Levels of RNA expression were determined using the 7500 Fast System SDS software package (version 1.3.1; Applied Biosystems; Thermo Fisher Scientific, Inc., Waltham, MA, USA).

RT-qPCR was performed in triplicate with an Applied Biosystems Prism 7500 Fast Sequence Detection System (Thermo Fisher Scientific, Inc., USA) using Takara universal PCR master mix, according to the manufacturer's protocol (Takara Bio, Inc., Otsu, Japan). Primers were purchased from Shanghai Shenggong Genetech Co. (Shanghai, China). $\beta$-actin was used as an endogenous control. Melting curve analysis was performed to verify specificity of PCR products. In addition, PCR products were electrophoresed on $2 \%$ agarose gel to confirm product sizes and specificity. The sequences were as follows: SPHK1 forward, 5'-CTTGCAGCTCTTCCGGAG TC-3' and reverse, 5'-GCTCAGTGAGCATCAGCGTG-3'; and $\beta$-actin forward, 5'-TCCTGTGGCATCCACGAAACT-3' and reverse, 5'-GAAGCATTTGCGGTGGACGAT-3'. Reaction conditions were set as follows: $95^{\circ} \mathrm{C}$ for $30 \mathrm{sec}$; followed by 40 cycles of $95^{\circ} \mathrm{C}$ for $5 \mathrm{sec}$; and $60^{\circ} \mathrm{C}$ for $34 \mathrm{sec}$. The association stage was set to check the specificity of primers as follows: $95^{\circ} \mathrm{C}$ for $15 \mathrm{sec}$; followed by $60^{\circ} \mathrm{C}$ for $1 \mathrm{~min} ; 95^{\circ} \mathrm{C}$ for $15 \mathrm{sec}$; and then $60^{\circ} \mathrm{C}$ for $15 \mathrm{sec}$. Each sample was performed in triplicate in a $20 \mu \mathrm{l}$ reaction volume. Relative quantification of gene expression was performed using the $2^{-\Delta \Delta \mathrm{Cq}}$ calculation formula, based on $\mathrm{Cq}$ values for target and reference genes (27).

Immunohistochemistry. A rabbit polyclonal antibody against human SPHK1 (cat. no., ab16491; dilution, 1:300; Abgent, Inc., San Diego, CA, USA) was used. Immunohistochemistry was performed using a two-step method. Sections $(4 \mu \mathrm{m})$ were deparaffinized by $100 \%$ xylene (4 times, 10 min each) and rehydrated in a series of ethanol $(100,95,85$ and $70 \%$ for $2 \mathrm{~min}$ each). The sections were hydrated and underwent sodium citrate $(\mathrm{pH}$ 6.0) antigen retrieval. Antigen retrieval was performed for $15 \mathrm{~min}$ in a microwave by intermittent heating to avoid boiling buffer, which may damage the tissue or dislodge it from the slide. Endogenous peroxidase activities were blocked by $3 \%$ hydrogen peroxide. The sections were then incubated with the primary antibody (cat. no., SP-9000; dilution, 1:250; Zhongshan Jinqiao) overnight for $18 \mathrm{~h}$ at $4^{\circ} \mathrm{C}$, followed by incubation with horseradish peroxidase-conjugated goat anti-rabbit immunoglobulin G secondary antibody (cat. no., SP-9000; dilution, 1:1,000; Zhongshan Jinqiao) at $37^{\circ} \mathrm{C}$ for $1 \mathrm{~h}$. Finally, slides were counterstained with hematoxylin. To eliminate nonspecific staining, a negative control was performed by replacing the primary antibody with PBS.

All staining was assessed by two pathologists blinded to the origination of the samples and subject outcome. The 


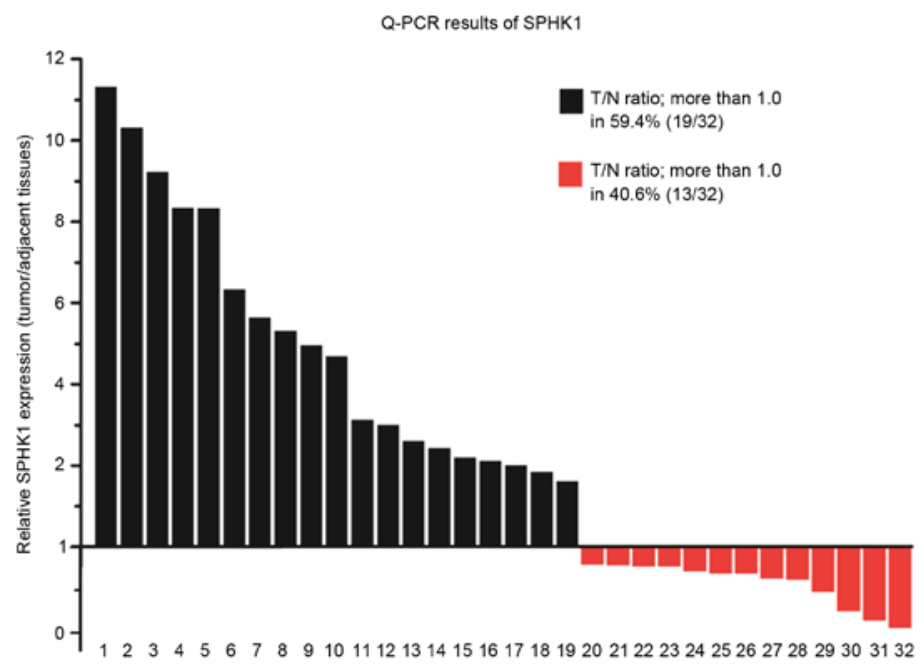

Figure 1. SPHK1 messenger RNA expression levels in 32 paired breast cancer and adjacent normal tissues of patients. T/N, tumor/normal; SPHK1, sphingosine kinase 1; Q-PCR, quantitative-polymerase chain reaction.

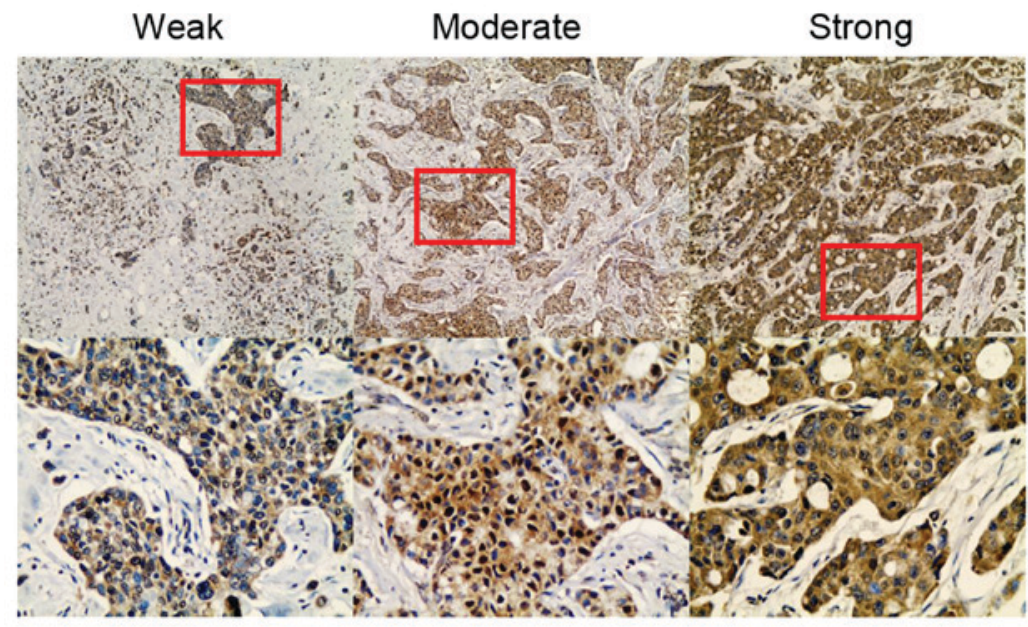

Figure 2. Immunohistochemical staining of SPHK1 in breast carcinomas. (left panel) Representative breast carcinomas stained weakly, moderately and strongly positive for SPHK1. Magnification, x10 (top) and x40 (bottom). SPHK1, sphingosine kinase 1.

widely accepted German semi-quantitative scoring system was used to assess the staining intensity and area extent (28). Each specimen was assigned a score according to the intensity of the nucleic, cytoplasmic and/or membrane staining (no staining, 0 ; weak staining, 1 ; moderate staining, 2 ; and strong staining, 3; and the extent of stained cells $(0 \%, 0 ; 1-24 \%$, $1 ; 25-49 \%, 2 ; 50-74 \%, 3$; and $75-100 \%, 4)$. The final score was calculated by multiplying the intensity score with the extent of staining score, ranging between 0 (the minimum score) and 12 (the maximum score). Scores $\geq 8$ were defined as high expression and scores $<8$ were defined as low expression.

Outcome of patients. Following a median follow-up of 56.5 months (7-106 months), 41 recurrence or metastasis cases and 22 mortalities occurred in all patients.

Statistical analysis. Statistical analysis was performed using SPSS 17.0 software (SPSS, Inc., Chicago, IL, USA). The OS time was counted from the date of diagnosis being confirmed as breast carcinoma to the date of last follow-up or mortality. Disease-free survival (DFS) time was calculated from the date of confirmed diagnosis to the date of last follow-up or metastatic diseases. $\chi^{2}$ and Fisher's exact tests were used to compare variables. Survival analysis was performed using the log-rank test, and survival plots were created using Kaplan-Meier methods. Multivariate analysis was performed using Cox proportional hazard regression analysis. All P-values reported were two-sided, and $\mathrm{P}<0.05$ was considered to indicate a statistically significant difference.

\section{Results}

Demographic and clinicopathological features. To validate the association between SPHK1, clinicopathological parameters and clinical outcome, an independent cohort of breast cancers with follow-up information was included in the present study. A total of 122 consecutive breast cancer specimens were collected, including 9 of carcinoma in situ and 113 of invasive 
Table I. Main characteristics of patients with breast cancer, and the association between the SPHK1 and clinicopathological parameters $(n=122)$.

SPHK1 expression

\begin{tabular}{|c|c|c|c|c|c|}
\hline Features & No. & High, n (\%) & Low, n (\%) & $\chi^{2}$ & P-value \\
\hline Age, & & & & 2.6011 & 0.1068 \\
\hline$<60$ years & 93 & $45(36.9)$ & $48(39.3)$ & & \\
\hline$\geq 60$ years & 29 & $19(15.6)$ & $10(8.2)$ & & \\
\hline Gravidity & & & & 0.8801 & 0.9321 \\
\hline 1 & 60 & $30(24.6)$ & $30(24.6)$ & & \\
\hline 2 & 22 & $12(9.8)$ & $10(8.2)$ & & \\
\hline 3 & 7 & $4(3.3)$ & $3(2.5)$ & & \\
\hline 4 & 11 & $7(5.7)$ & $4(3.3)$ & & \\
\hline$\geq 5$ & 5 & $3(2.5)$ & $2(1.6)$ & & \\
\hline Unknown & 17 & $7(5.7)$ & $10(8.2)$ & & \\
\hline Age at menarche, years & & & & 2.8928 & 0.4171 \\
\hline$\leq 12$ & 14 & $5(4.1)$ & $11(9.0)$ & & \\
\hline $13-14$ & 78 & $40(32.8)$ & $38(31.1)$ & & \\
\hline $15-16$ & 15 & $9(7.4)$ & $6(4.9)$ & & \\
\hline$\geq 17$ & 6 & $3(2.5)$ & $3(2.5)$ & & \\
\hline Missing data & 7 & $7(5.7)$ & $0(0)$ & & \\
\hline Initial symptoms & & & & 14.3048 & $0.0025^{\mathrm{a}}$ \\
\hline Lump & 92 & $39(32.0)$ & $53(43.5)$ & & \\
\hline Pain & 13 & $12(9.8)$ & $1(0.8)$ & & \\
\hline Nipple changes & 5 & $2(1.6)$ & $3(2.5)$ & & \\
\hline Clinical screening & 6 & $5(4.1)$ & $1(0.8)$ & & \\
\hline Unknown & 6 & $6(4.9)$ & $0(0)$ & & \\
\hline Tumor location & & & & 5.3123 & $0.0457^{\mathrm{a}}$ \\
\hline Right & 61 & $26(21.3)$ & $35(28.7)$ & & \\
\hline Left & 60 & $37(30.3)$ & $23(18.9)$ & & \\
\hline Both-sides & 1 & $1(0.8)$ & $0(0)$ & & \\
\hline Tumor histology & & & & 0.7865 & 0.3752 \\
\hline Carcinomas in situ & 9 & $6(4.9)$ & $3(2.5)$ & & \\
\hline Invasive carcinomas & 113 & $58(47.5)$ & $55(45.1)$ & & \\
\hline Types of invasive carcinomas & & & & 5.5517 & 0.0843 \\
\hline Ductal & 97 & $53(46.9)$ & $44(38.9)$ & & \\
\hline Lobular & 4 & $2(1.8)$ & $2(1.8)$ & & \\
\hline Mucinous adenocarcinoma & 5 & $0(0)$ & $5(4.4)$ & & \\
\hline Cephaloma & 2 & $1(0.9)$ & $1(0.9)$ & & \\
\hline Others & 5 & $2(1.8)$ & $3(2.6)$ & & \\
\hline Histological grade & & & & 2.9182 & 0.2531 \\
\hline I & 10 & $8(6.6)$ & $2(1.6)$ & & \\
\hline II & 70 & $38(31.1)$ & $32(26.3)$ & & \\
\hline III & 11 & $5(4.1)$ & $6(4.9)$ & & \\
\hline Unknown & 31 & $10(8.2)$ & $21(17.2)$ & & \\
\hline Tumor size, cm & & & & 0.4706 & 0.8883 \\
\hline$<2.0$ & 36 & $15(12.2)$ & $11(9.0)$ & & \\
\hline$\geq 2.0$ and $\leq 5.0$ & 78 & $39(32.0)$ & $39(32.0)$ & & \\
\hline$>5.0$ & 6 & $3(2.5)$ & $3(2.5)$ & & \\
\hline Unknown & 12 & $6(4.9)$ & $6(4.9)$ & & \\
\hline Lymph nodes status & & & & 10.3477 & $0.0013^{\mathrm{a}}$ \\
\hline Positive & 62 & $41(33.6)$ & $21(17.2)$ & & \\
\hline Negative & 55 & $20(16.4)$ & $35(28.7)$ & & \\
\hline Unknown & 5 & $3(2.5)$ & $2(1.6)$ & & \\
\hline
\end{tabular}


Table I. Continued.

\begin{tabular}{|c|c|c|c|c|c|}
\hline \multirow[b]{2}{*}{ Features } & \multirow[b]{2}{*}{ No. } & \multicolumn{2}{|c|}{ SPHK1 expression } & \multirow[b]{2}{*}{$\chi^{2}$} & \multirow[b]{2}{*}{ P-value } \\
\hline & & High, n (\%) & Low, n (\%) & & \\
\hline No. of positive lymph nodes & & & & 7.2395 & $0.0268^{\mathrm{a}}$ \\
\hline$<5$ & 92 & $42(34.4)$ & $50(41.0)$ & & \\
\hline $5-10$ & 16 & $11(9.0)$ & $5(4.1)$ & & \\
\hline$>10$ & 14 & $11(9.0)$ & $3(2.5)$ & & \\
\hline Distant metastasis & & & & 8.8374 & $0.0030^{\mathrm{a}}$ \\
\hline Positive & 32 & $24(19.7)$ & $8(6.5)$ & & \\
\hline Negative & 90 & $40(32.8)$ & $50(41.0)$ & & \\
\hline ER status & & & & 0.0104 & 0.9186 \\
\hline Positive & 57 & $29(23.8)$ & $26(21.3)$ & & \\
\hline Negative & 52 & $29(23.8)$ & $25(20.5)$ & & \\
\hline Unknown & 13 & $6(4.9)$ & $7(5.7)$ & & \\
\hline PR status & & & & 1.2539 & 0.2628 \\
\hline Positive & 38 & $23(18.9)$ & $15(12.3)$ & & \\
\hline Negative & 71 & $35(28.7)$ & $36(29.5)$ & & \\
\hline Unknown & 13 & $6(4.9)$ & $7(5.7)$ & & \\
\hline HER2 status & & & & 6.6422 & $0.0100^{\mathrm{a}}$ \\
\hline Positive & 44 & $30(24.6)$ & $14(11.5)$ & & \\
\hline Negative & 65 & $28(23.0)$ & $37(30.3)$ & & \\
\hline Unknown & 13 & $6(4.9)$ & $7(5.7)$ & & \\
\hline P53 status & & & & 0.0778 & 0.7803 \\
\hline Positive & 37 & $19(15.6)$ & $18(14.8)$ & & \\
\hline Negative & 72 & $39(32.0)$ & $33(27.0)$ & & \\
\hline Unknown & 13 & $6(4.9)$ & $7(5.7)$ & & \\
\hline Intrinsic subtype & & & & 1.5973 & 0.6600 \\
\hline Luminal A & 54 & $28(23.0)$ & $26(21.3)$ & & \\
\hline Luminal B & 7 & $4(3.3)$ & $3(2.5)$ & & \\
\hline HER2 type & 5 & $4(3.3)$ & $1(0.8)$ & & \\
\hline Basal-like & 43 & $22(18.0)$ & $21(17.2)$ & & \\
\hline Undefined & 13 & $6(4.9)$ & $7(5.7)$ & & \\
\hline
\end{tabular}

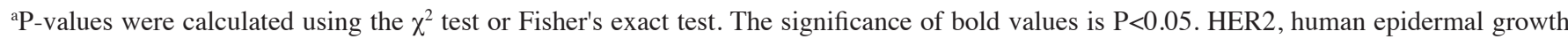
factor receptor 2; ER, estrogen receptor; PR, progesterone receptor; SPHK1, sphingosine kinase 1.

ductal carcinoma. The mean age of the total patients enrolled was 52 years, ranging from $27-75$ years. Histological types of the total 122 samples were defined according to the World Health Organization classification criteria (2007) into grade I (9 cases), grade II (76 cases), grade III (11 cases) and 26 cases with missing data.

SPHK1 mRNA expression. The mRNA level of SPHK1 in 32 tissues of patients, determined by RT-qPCR, revealed that the gene expression level of SPHK1 was significantly upregulated $(\mathrm{P}<0.0001)$. SPHK1 mRNA expression was upregulated [tumor/normal $(\mathrm{T} / \mathrm{N})$ ratio $>1$ ] in breast cancer tissues compared with that in matched adjacent breast tissues (expression=1) in 19 of 32 paired tissue specimens $(59.4 \%)$. In 13 of 32 specimens (40.6\%), SPHK1 was downregulated ( $\mathrm{T} / \mathrm{N}$ ratio $>1$; Fig. 1 ).
SPHK1 immunostaining. Immunohistochemical analysis was performed using 122 paraffin-embedded breast cancer tissue blocks to evaluate the expression of the SPHK1 protein. Negative staining was examined in all 15 normal breast cases (data not shown). Examples of the different SPHK1 staining of breast tumors are shown in Fig. 2, according to aforementioned methods. Positive staining for SPHK1 was mainly observed in the cytoplasm of the breast cancer cells. Among the 122 breast carcinomas, weak staining was observed in 26 specimens (21.3\%), moderate expression was observed in 57 (46.7\%) and strong staining was observed in 39 (32.0\%).

Association between SPHK1 expression and clinicopathological features. The association between the expression of SPHK1 and various clinicopathological parameters is listed in Table I. A significant association was observed between the high and low 


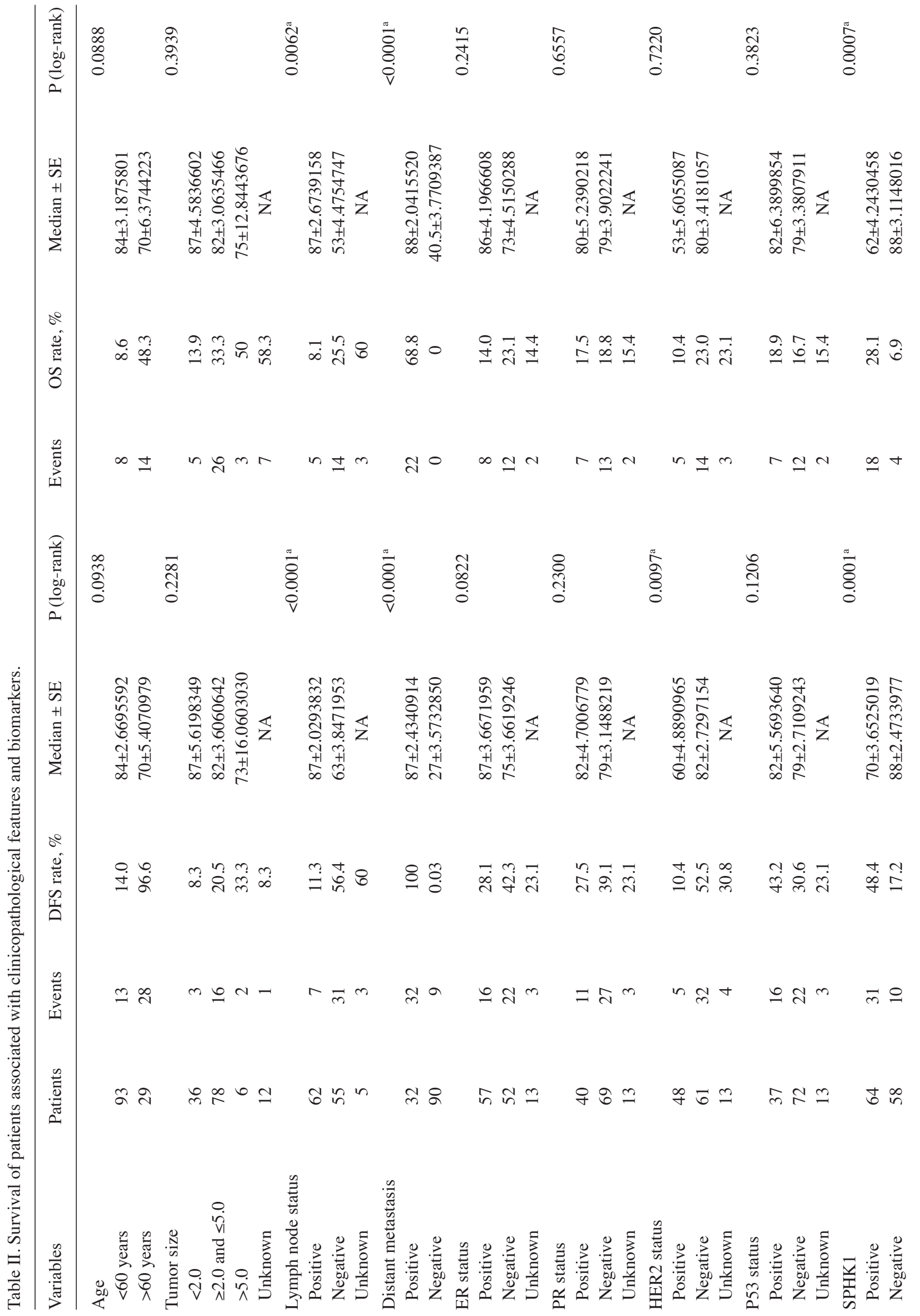




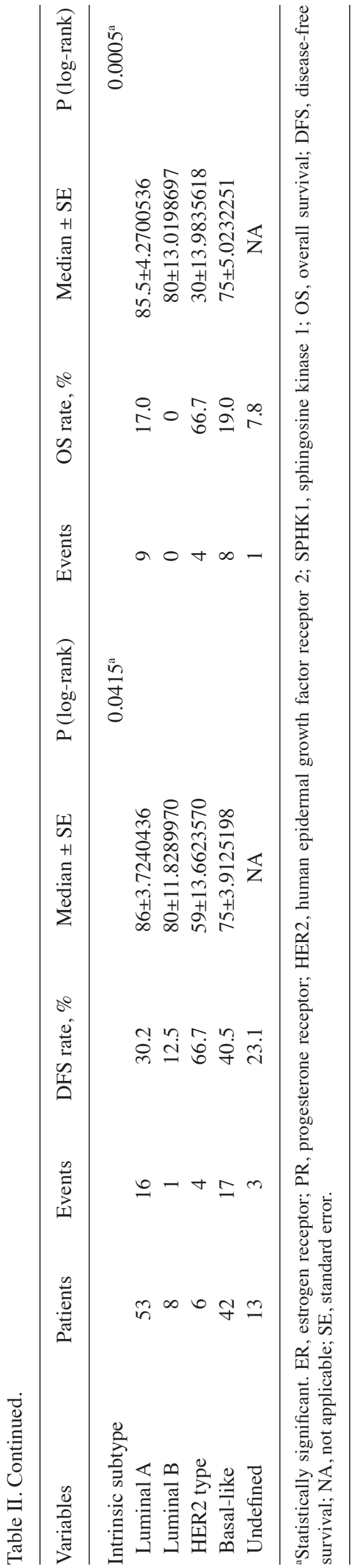

expression groups in the presence of lymph node metastasis $(\mathrm{P}=0.0016)$, number of positive lymph nodes $(\mathrm{P}=0.0268)$ and presence of distant metastasis $(\mathrm{P}=0.0097)$. High SPHK1 expression was also associated with human epidermal growth factor receptor 2 (HER2) status $(\mathrm{P}=0.0100)$, initial symptoms $(\mathrm{P}=0.0025)$ and tumor location $(\mathrm{P}=0.0457)$. However, no significant association was observed between the expression level of SPHK1 and age, times of pregnancy, age at menarche, tumor histological types, histological grade, tumor size or hormonal receptor (HR; estrogen receptor or progesterone receptor) status. There was also no significant difference in SPHK1 expression among the different intrinsic subtypes of breast cancer, as defined by the St Gallen consensus conference (29). These data showed that the expression of SPHK1 increases as breast cancer clinically progresses, but cancer intrinsic subtypes do not appear to be associated with the level of SPHK1 expression in the samples included in the present study.

SPHK1 expression and survival of patients. Survival curves plotted using the Kaplan-Meier method demonstrated that increased expression of SPHK1 was associated with a decrease in OS and DFS (Fig. 3). Statistical analysis of the impact of classic clinicopathological features and protein expression by the log-rank (Mantel-Cox) test revealed that patients with SPHK1-positive tumors had a significantly poorer prognosis than those with SPHK1-negative tumors $(\mathrm{P}<0.05)$. Other features associated with decreased survival were lymph node status, distant metastasis, HER2 status and intrinsic subtype, whereas other clinicopathological variables were not significant (Table II). By multivariate analysis, high SPHK1 expression was independently associated with greater cancer-specific OS (HR, 0.196; 95\% CI, 0.058-0.655; $\mathrm{P}=0.0081$; Table III).

\section{Discussion}

Breastcancer is one of the mostcommon malignancies worldwide; thus, it has been the object of intensive research, which is now revealing the complexity of this disease. It was initially reviewed that breast cancer dissemination is a non-random, organotropic process, originally based on Paget's theory of seed and soil, which suggests that disseminated cancer cells (seeds) can form metastases as they reach a microenvironment (soil), which is congenial enough for their survival and proliferation $(30,31)$. Nevertheless, how seeds fit in the exclusive soil has not been fully understood yet. The molecular subtypes of breast cancer have been proved to provide marginal metastasis site-specific prognostic information (32), but site-specific biomarkers with improved accuracy are required.

By contrast, the molecular mechanisms of tumor cell migration and metastasis to lymph nodes in vivo remain unclear, although several internal molecules in tumor cells have been reported to perform critical roles in the process of cell motility (33). Alteration in cell-cell adhesion and the secretion and activation of proteolytic enzymes is considered to be essential for optimal tumor cell invasion and migration through and across the extracellular barriers. In these aspects, several internal molecules have been reported to be associated with lymph node metastasis of breast carcinoma, including membrane-type 1 matrix metalloproteinase (34), 
Table III. Multivariate logistic regression analysis of different prognostic variables in patients with breast cancer by Cox regression analysis.

Multivariate analysis

\begin{tabular}{|c|c|c|c|c|c|c|}
\hline \multirow[b]{2}{*}{ Characteristics } & \multicolumn{3}{|c|}{ DFS } & \multicolumn{3}{|c|}{ OS } \\
\hline & P-value & $\mathrm{RR}$ & $\begin{array}{l}\text { Hazard ratio, } \\
\text { 95\% CI }\end{array}$ & P-value & $\mathrm{RR}$ & $\begin{array}{l}\text { Hazard ratio, } \\
95 \% \text { CI }\end{array}$ \\
\hline Age ( $<60$ vs. $\geq 60$ years $)$ & 0.4648 & 1.343 & $0.609-2.958$ & 0.4762 & 1.471 & $0.509-4.257$ \\
\hline $\begin{array}{l}\text { Lymph node metastasis } \\
\text { (yes vs. no) }\end{array}$ & $0.0003^{\mathrm{a}}$ & 6.067 & $2.28-16.082$ & $0.0299^{\mathrm{a}}$ & 3.530 & $1.131-11.020$ \\
\hline $\begin{array}{l}\text { SPHK1 expression } \\
\text { (positive vs. negative) }\end{array}$ & 0.0518 & 0.453 & $0.204-1.006$ & $0.0081^{\mathrm{a}}$ & 0.196 & $0.058-0.655$ \\
\hline ER (negative vs. positive) & 0.0671 & 3.339 & $0.919-12.131$ & $0.0411^{\mathrm{a}}$ & 5.107 & $1.068-24.422$ \\
\hline PR (negative vs. positive) & 0.5753 & 1.335 & $0.486-3.666$ & 0.3761 & 1.840 & $0.477-7.095$ \\
\hline HER2 score (negative & 0.3707 & 0.707 & $0.331-1.510$ & 0.2559 & 1.893 & $0.630-5.692$ \\
\hline
\end{tabular}

vs. positive)

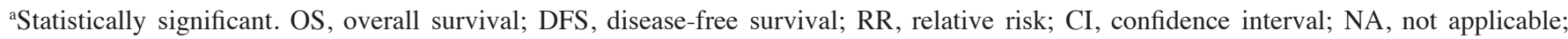
ER, estrogen receptor; PR, progesterone receptor; HER2, human epidermal growth factor receptor 2; SPHK1, sphingosine kinase 1.
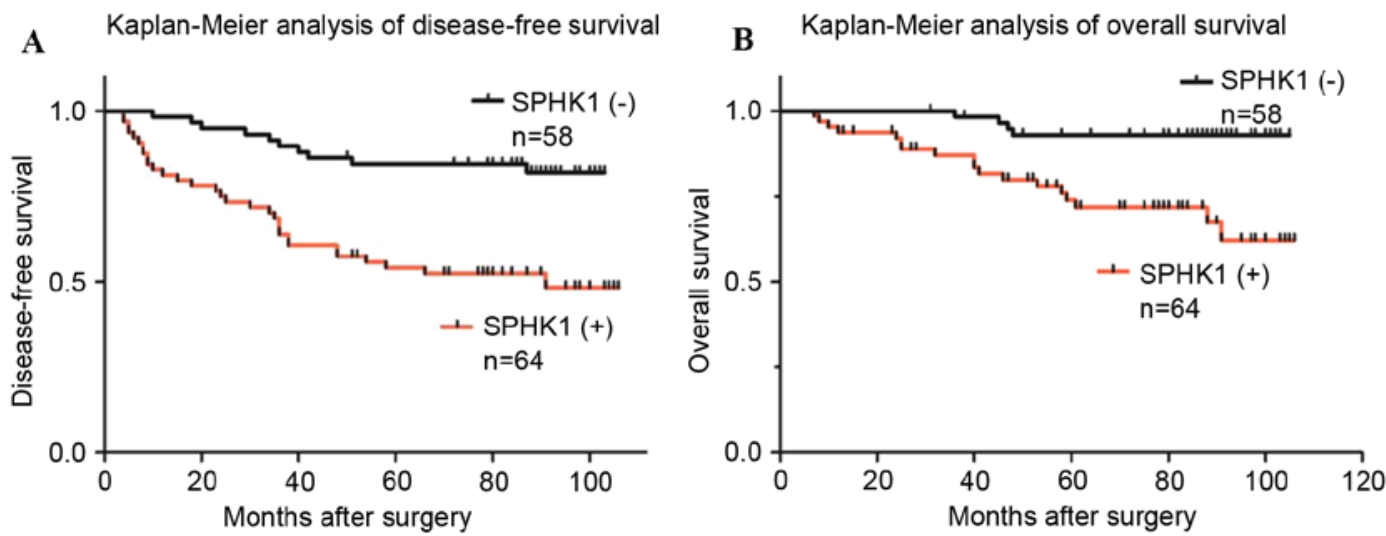

Figure 3. Kaplan-Meier survival curves for patients of (A) disease-free survival and (B) overall survival, according to the levels of SPHK1 expression. SPHK1, sphingosine kinase 1.

microRNA-21 (35) and vascular endothelial growth factor C (36). SPHK1 was previously identified to be involved in cervical cancer development and progression and its expression was associated with well-known prognostic parameters, including lymph node metastasis, lymphovascular invasion, tumor size, Federation of Gynecology and Obstetrics stage and invasion depth (37).

Multiple studies have revealed that SPHK1 is a key enzyme critical to the sphingolipid metabolic pathway, which serves a vital role in cancer progression. Studies have shown that ectopic expression of SPHK1 in NIH3T3 fibroblasts may promote the growth of cells in soft agar and the ability to form tumors in non-obese diabetic/severe combined immunodeficiency mice (6), and it may be due to its association with Ras and extracellular-signal regulated kinase 1/2 signaling (38). The expression of SPHK1 was revealed to be upregulated in breast cancer by using a microarray data of 1,269 tumor samples, and the expression status was positively associated with the survival of patients, indicating a potential prognostic value of this enzyme (39). It was suggested that SPHK1 is involved in EGF-mediated activation and migration of breast cancer MDA-MB-453 cells (40). Consistently, SPHK1 was revealed to be induced by transforming growth factor- $\beta$ (TGF- $\beta$ ) in fibroblasts and mesangioblasts, demonstrating that SPHK1 protein is an important component of the TGF- $\beta$ signaling pathway $(41,42)$. A previous study identified that the regulation of SPHK1 gene expression and kinase activity was mediated by TGF- $\beta$, which is critical to MDA-MB-231 cell viability (43).

These results support the evidence that SPHK1 has oncogenic potential in breast cancer progression. The prognostic role of SPHK1 has been studied in several cancer types, including gastric cancer (14) and astrocytoma (44), suggesting that patients with increased SPHK1 expression had shorter 
OS time, whereas those with lower SPHK1 survived longer. These studies indicate that SPHK1 is a prognostic indicator for a number of diseases. However, the roles of SPHK1 have not been extensively studied, particularly in the long-term survival of patients with breast cancer. In the present study, SPHK1 expression was associated with lymph node metastasis and the number of metastatic lymph nodes, indicating a role for SPHK1 in enhancing the progression of tumor cell migration and metastasis. Significant differences were also observed in other clinicopathological features and long-term prognosis among SPHK1-positive and SPHK1-negative samples. Previous studies along with the present study supported a hypothesis that SPHK1 is involved in functions other than its intracellular regulating function; it may also perform a vital role in breast cancer progression.

However, the present study has certain limitations, including a lack of intensive study into biological mechanisms involved in the association of SPHK1 expression and tumor metastasis. Additional investigations into the mechanisms of SPHK1 in breast cancer metastasis will be performed in future studies, using a larger sample size with longer follow-up time periods.

In conclusion, SPHK1 may be a potential novel drug-interfering target for cancer, and additional understanding of the function and molecular mechanisms of SPHK1 in regulating the progression of breast cancer may provide new insights into breast cancer therapy.

\section{Acknowledgments}

The authors would like to thank Ms. Ke Yang and Qian Liu from the Clinical and Pathological Diagnosis Center of Chongqing Medical University for technical support and assistance. The present study was supported by the National Natural Science Foundation of China to Dr Ke Zheng (grant no. 81202090).

\section{References}

1. Siegel R, Ma J, Zou Z and Jemal A: Cancer statistics, 2014. CA Cancer J Clin 64: 9-29, 2014.

2. Fan L, Strasser-Weippl K, Li JJ, St Louis J, Finkelstein DM, Yu KD, Chen WQ, Shao ZM and Goss PE: Breast cancer in China. Lancet Oncol 15: e279-e289, 2014.

3. Weigelt B, Peterse JL and van't Veer LJ: Breast cancer metastasis: Markers and models. Nat Rev Cancer 5: 591-602, 2005.

4. Espaillat MP, Shamseddine AA, Adada MM, Hannun YA and Obeid LM: Ceramide and sphingosine-1-phosphate in cancer, two faces of the sphinx. Transl Cancer Res 4: 484-499, 2015.

5. Wymann MP and Schneiter R: Lipid signalling in disease. Nat Rev Mol Cell Biol 9: 162-176, 2008.

6. XiaP, Gamble JR, Wang L,Pitson SM, Moretti PA, Wattenberg BW, D'Andrea RJ and Vadas MA: An oncogenic role of sphingosine kinase. Curr Biol 10: 1527-1530, 2000.

7. Limaye V, Li X, Hahn C, Xia P, Berndt MC, Vadas MA and Gamble JR: Sphingosine kinase-1 enhances endothelial cell survival through a PECAM-1-dependent activation of PI-3K/Akt and regulation of Bcl-2 family members. Blood 105: 3169-3177, 2005.

8. Maceyka M, Sankala H, Hait NC, Le Stunff H, Liu H, Toman R, Collier C, Zhang M, Satin LS and Merrill AH Jr, et al: SphK1 and SphK2, sphingosine kinase isoenzymes with opposing functions in sphingolipid metabolism. J Biol Chem 280: 37118-37129, 2005.

9. Igarashi N, Okada T, Hayashi S, Fujita T, Jahangeer S and Nakamura S: Sphingosine kinase 2 is a nuclear protein and inhibits DNA synthesis. J Biol Chem 278: 46832-46839, 2003.

10. Liu H, Toman RE, Goparaju SK, Maceyka M, Nava VE, Sankala H, Payne SG, Bektas M, Ishii I, Chun J, et al: Sphingosine kinase type 2 is a putative $\mathrm{BH} 3$-only protein that induces apoptosis. J Biol Chem 278: 40330-40336, 2003.
11. Wang Q, Li J, Li G, Li Y, Xu C, Li M, Xu G and Fu S: Prognostic significance of sphingosine kinase 2 expression in non-small cell lung cancer. Tumor Biol 35: 363-368, 2014.

12. French KJ, Schrecengost RS, Lee BD, Zhuang Y, Smith SN, Eberly JL, Yun JK and Smith CD: Discovery and evaluation of inhibitors of human sphingosine kinase. Cancer Res 63: 5962-5969, 2003.

13. Malavaud B, Pchejetski D, Mazerolles C, de Paiva GR, Calvet C, Doumerc N, Pitson S, Rischmann P and Cuvillier O: Sphingosine kinase-1 activity and expression in human prostate cancer resection specimens. Eur J Cancer 46: 3417-3424, 2010.

14. Li W, Yu CP, Xia JT, Zhang L, Weng GX, Zheng HQ, Kong QL, $\mathrm{Hu}$ LJ, Zeng MS, Zeng YX, et al: Sphingosine kinase 1 is associated with gastric cancer progression and poor survival of patients. Clin Cancer Res 15: 1393-1399, 2009.

15. Van Brocklyn JR, Jackson CA, Pearl DK, Kotur MS, Snyder PJ and Prior TW: Sphingosine kinase-1 expression correlates with poor survival of patients with glioblastoma multiforme: Roles of sphingosine kinase isoforms in growth of glioblastoma cell lines. J Neuropathol Exp Neurol 64: 695-705, 2005

16. Kohno M,Momoi M, Oo ML,Paik JH, Lee YM, Venkataraman K, Ai Y, Ristimaki AP, Fyrst H, Sano H, et al: Intracellular role for sphingosine kinase 1 in intestinal adenoma cell proliferation. Mol Cell Biol 26: 7211-7223, 2006.

17. Le Scolan E, Pchejetski D, Banno Y, Denis N, Mayeux P, Vainchenker W,Levade T and Moreau-Gachelin F: Overexpression of sphingosine kinase 1 is an oncogenic event in erythroleukemic progression. Blood 106: 1808-1816, 2005.

18. Liu SQ, Su YJ, Qin MB, Mao YB, Huang JA and Tang GD: Sphingosine kinase 1 promotes tumor progression and confers malignancy phenotypes of colon cancer by regulating the focal adhesion kinase pathway and adhesion molecules. Int J Oncol 42: 617-626, 2013.

19. Liu G, Zheng H, Zhang Z, Wu Z, Xiong H, Li J and Song L: Overexpression of sphingosine kinase 1 is associated with salivary gland carcinoma progression and might be a novel predictive marker for adjuvant therapy. BMC Cancer 10: 495, 2010.

20. Guan H, Song L, Cai J, Huang Y, Wu J, Yuan J, Li J and Li M: Sphingosine kinase 1 regulates the Akt/FOXO3a/Bim pathway and contributes to apoptosis resistance in glioma cells. PLoS One 6: e19946, 2011.

21. Akao Y, Banno Y, Nakagawa Y, Hasegawa N, Kim TJ, Murate T, Igarashi $Y$ and Nozawa Y: High expression of sphingosine kinase 1 and $\mathrm{S} 1 \mathrm{P}$ receptors in chemotherapy-resistant prostate cancer PC3 cells and their camptothecin-induced up-regulation. Biochem Biophys Res Commun 342: 1284-1290, 2006.

22. Kawamori T, Osta W, Johnson KR, Pettus BJ, Bielawski J, Tanaka T, Wargovich MJ, Reddy BS, Hannun YA, Obeid LM and Zhou D: Sphingosine kinase 1 is up-regulated in colon carcinogenesis. FASEB J 20: 386-388, 2006.

23. Pchejetski D, Golzio M, Bonhoure E, Calvet C, Doumerc N, Garcia V, Mazerolles C, Rischmann P, Teissié J, Malavaud B and Cuvillier O: Sphingosine kinase-1 as a chemotherapy sensor in prostate adenocarcinoma cell and mouse models. Cancer Res 65: 11667-11675, 2005.

24. Sarkar S, Maceyka M, Hait NC, Paugh SW, Sankala H, Milstien S and Spiegel S: Sphingosine kinase 1 is required for migration, proliferation and survival of MCF-7 human breast cancer cells. FEBS Lett 579: 5313-5317, 2005

25. Datta A, Loo SY, Huang B, Wong L, Tan SS, Tan TZ, Lee SC, Thiery JP, Lim YC, Yong WP, et al: SPHK1 regulates proliferation and survival responses in triple-negative breast cancer. Oncotarget 5: 5920-5933, 2014.

26. Luo HJ, Chen X, Tu G, Wang J, Wu CY and Yang GL: Therapeutic application of ultrasound-guided 8-gauge mammotome system in presumed benign breast lesions. Breast J 17: 490-497, 2011.

27. Livak KJ and Schmittgen TD: Analysis of relative gene expression data using real-time quantitative PCR and the 2(-Delta Delta C(T)) Method. Methods 25: 402-408, 2001.

28. Pan X, Zhou T, Tai YH, Wang C, Zhao J, Cao Y, Chen Y, Zhang PJ, Yu M, Zhen C, et al: Elevated expression of CUEDC2 protein confers endocrine resistance in breast cancer. Nat Med 17: 708-714, 2011.

29. Goldhirsch A, Wood W, Coates A, Gelber R, Thürlimann B and Senn HJ; Panel members: Strategies for subtypes-dealing with the diversity of breast cancer: Highlights of the St. Gallen International Expert Consensus on the Primary Therapy of Early Breast Cancer 2011. Ann Oncol 22: 1736-1747, 2011.

30. Paget S: The distribution of secondary growths in cancer of the breast. Cancer Metastasis Rev 8: 98-101, 1889. 
31. Fidler IJ: The pathogenesis of cancer metastasis: The 'seed and soil' hypothesis revisited. Nat Rev Cancer 3: 453-458, 2003.

32. Rakha EA, El-Sayed ME, Green AR, Lee AH, Robertson JF and Ellis IO: Prognostic markers in triple-negative breast cancer. Cancer 109: 25-32, 2007.

33. Wang W, Goswami S, Sahai E, Wyckoff JB, Segall JE and Condeelis JS: Tumor cells caught in the act of invading: Their strategy for enhanced cell motility. Trends Cell Biol 15: 138-145, 2005.

34. Yao G, He P, Chen L, Hu X, Gu F and Ye C: MT1-MMP in breast cancer: Induction of VEGF-C correlates with metastasis and poor prognosis. Cancer Cell Int 13: 98, 2013.

35. Yan LX, Huang XF, Shao Q, Huang MY, Deng L, Wu QL, Zeng YX and Shao JY: MicroRNA miR-21 overexpression in human breast cancer is associated with advanced clinical stage, lymph node metastasis and patient poor prognosis. RNA 14: 2348-2360, 2008.

36. Skobe M, Hawighorst T, Jackson DG, Prevo R, Janes L, Velasco P, Riccardi L, Alitalo K, Claffey K and Detmar M: Induction of tumor lymphangiogenesis by VEGF-C promotes breast cancer metastasis. Nat Med 7: 192-198, 2001.

37. Kim HS, Yoon G, Ryu JY, Cho YJ, Choi JJ, Lee YY, Kim TJ, Choi CH, Song SY, Kim BG, et al: Sphingosine kinase 1 is a reliable prognostic factor and a novel therapeutic target for uterine cervical cancer. Oncotarget 6: 26746-26756, 2015.

38. Shu X, Wu W, Mosteller RD and Broek D: Sphingosine kinase mediates vascular endothelial growth factor-induced activation of ras and mitogen-activated protein kinases. Mol Cell Biol 22: 7758-7768, 2002.
39. Ruckhäberle E, Rody A, Engels K, Gaetje R, von Minckwitz G, Schiffmann S, Grösch S, Geisslinger G, Holtrich U, Karn T and Kaufmann M: Microarray analysis of altered sphingolipid metabolism reveals prognostic significance of sphingosine kinase 1 in breast cancer. Breast Cancer Res Treat 112: 41-52, 2008.

40. Hait NC, Sarkar S, Le Stunff H, Mikami A, Maceyka M, Milstien S and Spiegel S: Role of sphingosine kinase 2 in cell migration toward epidermal growth factor. J Biol Chem 280: 29462-29469, 2005.

41. Yamanaka M, Shegogue D, Pei H, Bu S, Bielawska A, Bielawski J, Pettus B, Hannun YA, Obeid L and Trojanowska M: Sphingosine kinase 1 (SPHK1) is induced by transforming growth factor-beta and mediates TIMP-1 up-regulation. J Biol Chem 279: 53994-54001, 2004

42. Donati C, Cencetti F, De Palma C, Rapizzi E, Brunelli S, Cossu G, Clementi E and Bruni P: TGFbeta protects mesoangioblasts from apoptosis via sphingosine kinase-1 regulation. Cell Signal 21: 228-236, 2009.

43. Stayrook KR, Mack JK, Cerabona D, Edwards DF, Bui HH, Niewolna M, Fournier PG, Mohammad KS, Waning DL and Guise TA: TGF $\beta$-mediated induction of SphK1 as a potential determinant in human MDA-MB-231 breast cancer cell bone metastasis. Bonekey Rep 4: 719, 2015.

44. Li J, Guan HY, Gong LY, Song LB, Zhang N, Wu J, Yuan J, Zheng YJ, Huang ZS and Li M: Clinical significance of sphingosine kinase-1 expression in human astrocytomas progression and overall patient survival. Clin Cancer Res 14: 6996-7003, 2008. 